\title{
Factors affecting prognosis in myelofibrosis
}

\section{Francesco Onida}

\author{
Address: Hematology I - Bone Marrow Transplantation Center, Fondazione IRCCS Ospedale Maggiore Policlinico, Mangiagalli e Regina Elena, \\ University of Milan, Via Francesco Sforza 35, 20122 Milan, Italy \\ Email: francesco.onida@unimi.it
}

FI000 Medicine Reports 2009, I:55 (doi:I0.34I0/MI-55)

The electronic version of this article is the complete one and can be found at: http://FI000.com/Reports/Medicine/content/I/55

\begin{abstract}
Studies investigating factors affecting prognosis in primary myelofibrosis have been numerous over the years because of the high heterogeneity with regard to its natural clinical course. Recently, the increasing application of reduced-intensity conditioning with allogeneic hematopoietic stem cell transplantation as well as the ongoing rapid development of new experimental agents, such as JAK2 inhibitors, have made the requirement for simple and accurate scoring systems to select individual patients for the most appropriate treatment strategy even more critical. This short report summarizes the state of the art and the most recent advances in this area.
\end{abstract}

\section{Introduction and context}

Primary myelofibrosis (PMF), also known as agnogenic myeloid metaplasia or chronic idiopathic myelofibrosis, is definitely the most heterogeneous among the Philadelphia chromosome $(\mathrm{Ph})$-negative chronic myeloproliferative diseases with regard to clinical characteristics and natural disease history. As a consequence, life expectation of patients diagnosed with this malignancy can vary from very few to several years, depending on a variety of disease and patient characteristics. Even though new agents (in particular the JAK2 tyrosine-kinase inhibitors) currently under investigation appear promising, to date allogeneic hematopoietic stem cell transplantation (alloHSCT) remains the only potentially curative treatment approach for patients with PMF. Because this disease occurs mainly in middle aged and elderly patients, with a median age at presentation of 67 years [1], transplant strategies are mainly based on reduced intensity conditioning (RIC) regimens [2,3]. Indeed, in the recent years RIC allo-HSCT has increasingly been investigated [4-8] with encouraging results. Therefore, identification of prognostic factors in PMF is crucial in order to select patients who might benefit from allogeneic transplantation, as well as patients who could be enrolled in trials investigating new agents with partially unknown toxicity.
Patient and disease characteristics associated with shorter survival by multivariate analyses performed in large retrospective series of patients with PMF in the past 15 years [9-12] are summarized in Table 1. Among all factors independently associated with a poorer prognosis, anemia has constantly appeared to be one of the most important and has thus invariably been included in all the scoring systems proposed to stratify patients according to the risk of death from the disease [9-13]. In particular, the proportion of PMF patients reported as having a hemoglobin level of $<10 \mathrm{~g} / \mathrm{dL}$ at diagnosis ranged from $35-44 \%$, depending on the series, while patients presenting with a hemoglobin level of $<8 \mathrm{gm} / \mathrm{dL}$ were reported to represent $20 \%$ of all PMF patients [13]. The causes of anemia in PMF are various, with reduction in medullary erythropoiesis, ineffective extramedullary erythropoiesis and splenic destruction of circulating red blood cells being the most important.

As in other hematological malignancies, advanced age is also associated with a worse prognosis in PMF [9]. However, because in some studies the identification of adverse features has been especially aimed at allowing selection of patients who could be eligible for allo-HSCT - that is, they have included in the analyses 
Table I. Factors associated with shorter survival by multivariate analysis in four published studies on PMF patients and the ensuing scoring systems

\begin{tabular}{|c|c|c|c|c|}
\hline Risk factor & $\begin{array}{l}\text { Dupriez et al. [9] } \\
\text { (195 pts) }\end{array}$ & $\begin{array}{l}\text { Cervantes et al. [10] } \\
(121 \text { pts*) }\end{array}$ & $\begin{array}{l}\text { Dingli et al. [II] } \\
\left(160 \mathrm{pts}^{\dagger}\right)\end{array}$ & $\begin{array}{l}\text { Elliott et al. [12] } \\
\left(129 \mathrm{pts}^{\dagger}\right)\end{array}$ \\
\hline Hemoglobin (g/dL) & $<10^{\ddagger}$ & \multirow[t]{4}{*}{$<10^{\ddagger}$} & $<10^{\ddagger}$ & \multirow[t]{2}{*}{$<10^{\ddagger}$} \\
\hline Age (years) & $>60$ & & & \\
\hline WBC $\left(\times 10^{9} / \mathrm{L}\right)$ & $<4,>30^{\ddagger}$ & & $<4,>30^{\ddagger}$ & $<4,>30^{\ddagger}$ \\
\hline Platelets $\left(\times 10^{6} / \mathrm{L}\right)$ & & & $<100^{\ddagger}$ & $<100^{\ddagger}$ \\
\hline Peripheral blasts (\%) & $>2$ & \multirow[t]{2}{*}{$\geq 1^{\ddagger}$} & & \\
\hline Monocytes $\left(\times 10^{9} / \mathrm{L}\right)$ & & & & \multirow[t]{4}{*}{$>1.0^{\ddagger}$} \\
\hline Constitutional symptoms & Present & \multirow[t]{4}{*}{ Present ${ }^{\ddagger}$} & Present & \\
\hline Hepatomegaly & & & Present & \\
\hline Sex & Male & & & \\
\hline Karyotype & Abnormal & & Unfavorable & Unfavorable \\
\hline Prognostic risk groups & Low (93) & Low (I76) & Low (155) & Low (173) \\
\hline (median survival in & Interm (26) & High (33) & Interm (69) & Interm (6I) \\
\hline months) & High (13) & & High (23.5) & High (26) \\
\hline
\end{tabular}

*Patients included in this study were aged $\leq 55$ years. ${ }^{\dagger}$ Patients included in this study were aged $\leq 60$ years. ${ }^{\star}$ Factors included in the ensuing scoring system. Interm, intermediate; PMF, primary myelofibrosis; pts, patients; WBC, white blood cell.

only young patients - age has not always appeared to be significantly associated with shorter survival [10-12].

With regard to the total leukocyte count at presentation, both leukocytopenia (with white blood cell counts lower than $4 \times 10^{9} / \mathrm{L}$ ) and leukocytosis (with white blood cell counts higher than $30 \times 10^{9} / \mathrm{L}$ ) have consistently been reported as independently associated with inferior survival [10-12] in PMF.

Circulating blasts or circulating immature granulocytes have been associated with shorter survival in most studies $[9,10,13]$, whereas the absolute content of CD34+ cells in the peripheral blood, which has been associated with both shorter survival and a smaller interval to blast transformation in one study [14], correlated with the presence of blood blasts but not with survival in other patient populations when adjusted by other covariates $[15,16]$.

Thrombocytopenia (platelet counts $<100 \times 10^{9} / \mathrm{L}$ ), which is seen in $25 \%$ of patients at diagnosis [15] and becomes more common with disease progression, was incorporated among the adverse prognostic factors in the complete blood count (CBC)-based scoring systems recently published by the Mayo Clinic $[11,12]$.

Constitutional symptoms, including severe fatigue, weight loss, low-grade fever, and night sweats are quite common in PMF, especially when patients develop massive hepatosplenomegaly, and represent a well-established risk-factor finding according to most authors [9-11].

With regard to cytogenetics, in PMF the high frequency of 'dry tap' during bone marrow aspirate makes it difficult to obtain assessable metaphases for the analysis of karyotypes. Nonetheless, the negative prognostic impact of cytogenetic abnormalities in PMF has been indicated by several studies [17-20]. Also, even if generally not included in the scoring systems, cytogenetic abnormalities emerged as independent factors in all the retrospective multivariate analyses performed on the largest series of patients [9-11].

\section{Recent advances}

At the end of 2008, the International Working Group for Myelofibrosis Research and Treatment (IWG-MRT) published the results of a prominent multicenter retrospective study that included 1,054 patients consecutively diagnosed with PMF, representing the largest patient population ever analyzed [15], with the aim of identifying adverse prognostic factors. The series included patients of all ages from the databases of seven important reference institutions and led to the proposal of a new simple prognostic model based on five risk factors (Tables 2 and 3).

Table 2. Factors associated with shorter survival by multivariate analysis in the study by the IWG-MRT [15]

\begin{tabular}{ll}
\hline Risk factor & Hazard ratio $(95 \% \mathrm{Cl})$ \\
\hline Age $>65$ years & $1.95(1.61-2.36)$ \\
Constitutional symptoms & $1.97(1.62-2.40)$ \\
Hemoglobin $<10 \mathrm{~g} / \mathrm{dL}$ & $2.89(2.46-3.6 \mathrm{I})$ \\
WBC count $>25 \times 10^{9} / \mathrm{L}$ & $2.40(1.83-3.14)$ \\
Peripheral blasts $\geq 1 \%$ & $1.80(1.50-2.17)$ \\
\hline
\end{tabular}

$\mathrm{Cl}$, confidence interval; $\mathrm{WBC}$, white blood cell. This research was originally published in Blood. Cervantes et al. A new prognostic scoring system for primary myelofibrosis based on a study of the International Working Group for Myelofibrosis Research and Treatment. Blood 2008, II3:2895-90I. (c) American Society of Hematology. 
Table 3. New scoring system for PMF proposed by the IWG-MRT [15]

\begin{tabular}{lll}
\hline Risk group & No. of factors & Median survival $(95 \% \mathrm{Cl})$ \\
\hline Low & 0 & 135 months $(\mathrm{II}-\mathrm{I}-\mathrm{I} \mathrm{I})$ \\
Intermediate-I & $\mathrm{I}$ & 95 months $(79-\mathrm{II} 4)$ \\
Intermediate-2 & 2 & 48 months $(43-59)$ \\
High & $\geq 3$ & 27 months (23-3I) \\
\hline
\end{tabular}

$\mathrm{Cl}$, confidence interval; IWG-MRT, International Working Group for Myelofibrosis Research and Treatment; PMF, primary myelofibrosis. This research was originally published in Blood. Cervantes et al. A new prognostic scoring system for primary myelofibrosis based on a study of the International Working Group for Myelofibrosis Research and Treatment. Blood 2008, I 13:2895-901. () American Society of Hematology.

Unlike in almost all previous similar reports, in this study leukocytosis (with $25 \times 10^{9} / \mathrm{L}$ as the best cut-off level for the white blood cell count) but not leukocytopenia was shown to retain prognostic significance by multivariate analysis [15]. Interestingly, a strong association between thrombocytopenia and anemia was unveiled, so that thrombocytopenia did not have prognostic significance in anemic patients, while anemia retained its prognostic value in both patients with and without thrombocytopenia [15].

Besides leukocytosis and anemia, the IWG-MRT analysis pointed towards an age $>65$ years, presence of constitutional symptoms, and circulating blasts $\geq 1 \%$ as other independent risk factors associated with shorter survival in PMF (Table 2) [15].

The prognostic role of absolute monocytosis (that is, monocytes count greater than $1 \times 10^{9} / \mathrm{L}$ ) in PMF is controversial. In fact, although in 2007 a renovated analysis performed by the Mayo Clinic [12] in a very well-selected PMF patient population demonstrated that the inclusion of monocytosis among factors previously incorporated in their simple CBC-based 'Mayo' prognostic scoring system [11] (that is, hemoglobin level, leukocyte count and platelet count) led to a better risk stratification of patients with PMF in comparison to other accepted scoring systems [9-11], the poor prognostic influence of a high monocyte count was not confirmed in the most recent analysis of the IWG-MRT. Nonetheless, it should be emphasized that in this latter study differential counts were available in only $64 \%$ of cases [15].

Regarding cytogenetics, it is worth mentioning that an association of abnormal karyotypes with shorter survival was also observed in the IWG-MRT study, although by the multivariate Cox model this factor emerged as contributing to prognosis only in the two intermediaterisk groups [15].
Although variable, some degree of marrow fibrosis is seen in almost all patients with myelofibrosis, and is therefore considered the hallmark of this disease. Grading of myelofibrosis in trephine bone marrow biopsies, however, is mainly based on subjective evaluation by individual pathologists. Therefore, in 2005 a European consensus recommended the use of four easily reproducible categories (MF-0, MF-1, MF-2, MF-3) for bone marrow fibrosis [21]. A recent study addressed the question of whether bone marrow fibrosis grading may play a prognostic role in PMF by analyzing 98 patients diagnosed with the disease strictly in accordance with the last World Health Organization criteria [22], actually showing that survival was significantly shorter in the patients with MF-3 than in those with lower stages of fibrosis [23].

The frequency of the JAK2 V617F mutation ranges from 43-63\% in PMF, but its prognostic impact is currently unclear. Indeed, the mutation was associated with shorter survival in one retrospective study of 152 patients [24], whereas a subsequent prospective study including 174 patients demonstrated a correlation between the V617F mutation and evolution towards large splenomegaly, need for splenectomy, and leukemic transformation, but not survival [25]. Similarly, no association of the JAK2 mutation with survival was observed in a series of 117 patients from the Mayo Clinic [26]. In the most recent study by the IWG-MRT, no association with survival was observed, but it should be remarked that information on the JAK2 V617F mutation status was available for only $33 \%$ of the patients included in the study [15].

Although rare, transformation to acute leukemia is a possible event in PMF. However, most prognostic studies in this disease have focused on risk factors for overall survival. In 2008, clinical variables at the time of diagnosis and specific treatment modalities were analyzed for their effect on leukemic transformation in 311 patients with primary myelofibrosis [27]. By multivariate analysis, circulating blasts $\geq 3 \%$ and platelet count $<100 \times 10^{9} / \mathrm{L}$ were found to be independent predictors of leukemic transformation. The evaluation of treatment effect on leukemic transformation surprisingly revealed an independent association with previous erythropoiesis-stimulating agents or danazol, even when the aforementioned prognostic indicators at the time of diagnosis were added as covariates to the multivariate model, obviously demanding further validation by prospective studies.

\section{Implications for clinical practice}

The identification of prognostic factors in PMF that might be used to design scoring systems able to stratify patients 
at diagnosis according to the risk of death from the disease is critical and has considerable practical implications. Indeed, scoring systems could allow selection of patients who might be candidates for allo-HSCT, conventional or experimental drug therapy, or strategies based on watchful waiting, depending on the individual level of risk.

In comparison to previous ones [9-13], the new scoring system proposed by the IWG-MRT has higher discriminating power, showing high reproducibility and predictive accuracy [15]. In particular, this system was shown to discriminate four risk groups with no overlap of their survival curves (Table 3). Because this model was identified through a retrospective analysis of a very large PMF population including patients of all ages, it should also be particularly helpful in stratifying risk categories according to life expectations among elderly patients, who, in highly selected cases, might still benefit from a RIC allo-HSCT treatment-based strategy. At the same time, the new IWG-MRT scoring system could be applied to discriminate between patients with very low risk who should only be observed over time, and those whose level of risk might justify their enrolment in trials with new experimental drugs.

Nonetheless, even though the risks of morbidity and mortality associated with allo-HSCT have decreased with the introduction of RIC regimens, they still remain significant, so when selecting patients for this treatment it is crucial to not only bear in mind the risk of death from the disease but also to take into account the risk of death from the transplant procedure [28]. In any case, allo-HSCT should still be considered an experimental treatment in PMF, and should be performed only in the context of controlled clinical trials.

To conclude, it is important to stress that all the PMF prognostic scores so far developed, including the new IWG-MRT scoring system, apply only to patients at diagnosis. However, because we do not have other criteria, in clinical practice we also utilize these scores after initial treatments, or at the time of disease progression. Indeed, as for other hematological malignancies, allogeneic transplants performed in low-risk versus intermediate/high-risk PMF patients have different outcomes. It should be noted, however, that no study has proven that the previously most widely applied classification system (the Lille score) [9] and the following ones, including the new IWG-MRT score [10-12,15], have the same utility when used at times other than diagnosis.

\section{Abbreviations}

allo-HSCT, allogeneic hematopoietic stem cell transplantation; CBC, complete blood count; IWG-MRT,
International Working Group for Myelofibrosis Research and Treatment; JAK2, Janus kinase 2; PMF, primary myelofibrosis; RIC, reduced intensity conditioning.

\section{Competing interests}

The author declares that he has no competing interests.

\section{References}

I. Mesa RA, Silverstein MN, Jacobsen SJ, Wollan PC, Tefferi A: Population-based incidence and survival figures in essential thrombocythemia and agnogenic myeloid metaplasia: an Olmsted County Study, 1976-1995. Am J Hematol 1999, 6 I:10-5.

2. Mittal P, Saliba RM, Giralt SA, Shahjahan M, Cohen AI, Karandish S, Onida F, Beran M, Champlin RE, de Lima M: Allogeneic transplantation: a therapeutic option for myelofibrosis, chronic myelomonocytic leukemia and Philadelphia-negative/BCR-ABL-negative chronic myelogenous leukemia. Bone Marrow Transplant 2004, 33:1005-9.

3. Ditschkowski M, Beelen DW, Trenschel R, Koldehoff $M$, Elmaagacli $\mathrm{AH}$ : Outcome of allogeneic stem cell transplantation in patients with myelofibrosis. Bone Marrow Transplant 2004, 34:807-13.

4. Rondelli D, Barosi G, Bacigalupo A, Prchal JT, Popat U, Alessandrino EP, Spivak JL, Smith BD, Klingemann HG, Fruchtman S, Hoffman R; Myeloproliferative Diseases-Research Consortium: Allogeneic hematopoietic stem-cell transplantation with reduced-intensity conditioning in intermediate- or high-risk patients with myelofibrosis with myeloid metaplasia. Blood 2005, I 05:4| I5-9.

5. Merup M, Lazarevic V, Nahi H, Andreasson B, Malm C, Nilsson L, Brune M, LeBlanc K, Kutti J, Birgegård G; Swedish Group for Myeloproliferative Disorders: Different outcome of allogeneic transplantation in myelofibrosis using conventional or reduced-intensity conditioning regimens. Br J Haematol 2006, 135:367-73.

6. Snyder DS, Palmer J, Stein AS, Pullarkat V, Sahebi F, Cohen S, Vora N, Gaal K, Nakamura R, Forman SJ: Allogeneic hematopoietic cell transplantation following reduced intensity conditioning for treatment of myelofibrosis. Biol Blood Marrow Transplant 2006, 12: | |6|-8.

7. Kröger N, Thiele J, Zander A, Schwerdtfeger R, Kobbe G, Bornhäuser M, Bethge W, Schubert J, de Witte T, Kvasnicka HM; MDS-Subcommittee of the Chronic Leukaemia Working Party of the European Group for Blood and Marrow Transplantation: Rapid regression of bone marrow fibrosis after dose-reduced allogeneic stem cell transplantation in patients with primary myelofibrosis. Exp Hematol 2007, 35:1719-22.

8. Kröger $\mathrm{N}$, Alchalby $\mathrm{H}$, Klyuchnikov E, Badbaran A, Hildebrandt $\mathrm{Y}$, Ayuk F, Bacher U, Bock O, Kvasnicka M, Fehse B, Zander A: JAK2V6I7F-triggered preemptive and salvage adoptive immunotherapy with donor-lymphocyte infusion in patients with myelofibrosis after allogeneic stem cell transplantation. Blood 2009, I | 3: 1866-8.

9. Dupriez B, Morel P, Demory JL, Lai JL, Simon M, Plantier I, Bauters F: Prognostic factors in agnogenic myeloid metaplasia: a report on 195 cases with a new scoring system. Blood 1996, 88: 1013-8.

10. Cervantes F, Barosi G, Demory JL, Reilly J, Guarnone R, Dupriez B, Pereira A, Montserrat E: Myelofibrosis with myeloid metaplasia in young individuals: disease characteristics, prognostic factors and identification of risk groups. Br J Haematol 1998 , 102:684-90.

II. Dingli D, Schwager SM, Mesa RA, Li CY, Tefferi A: Prognosis in transplant-eligible patients with agnogenic myeloid metaplasia: a simple CBC-based scoring system. Cancer 2006, 106:62330.

12. Elliott MA, Verstovsek S, Dingli D, Schwager SM, Mesa RA, Li CY, Tefferi A: Monocytosis is an adverse prognostic factor for 
survival in younger patients with primary myelofibrosis. Leuk Res 2007, 31 : I 503-9.

FI000 Factor 3.0 Recommended

Evaluated by Francesco Onida 01 Feb 08

13. Visani G, Finelli C, Castelli U, Petti MC, Ricci P, Vianelli N, Gianni L, Zuffa E, Aloe Spiriti MA, Latagliata R, Pileri S, Magrini U, Gugliotta L, Morra E, Bernasconi C, Mandelli F, Tura S: Myelofibrosis with myeloid metaplasia: clinical and haematological parameters predicting survival in a series of 133 patients. $\mathrm{Br} J$ Haematol 1990, 75:4-9.

14. Barosi G, Viarengo G, Pecci A, Rosti V, Piaggio G, Marchetti M, Frassoni F: Diagnostic and clinical relevance of the number of circulating CD34(+) cells in myelofibrosis with myeloid metaplasia. Blood 200I, 98:3249-55.

15. Cervantes F, Dupriez B, Pereira A, Passamonti F, Reilly JT, Morra E, Vannucchi AM, Mesa RA, Demory JL, Barosi G, Rumi E, Tefferi A: A new prognostic scoring system for primary myelofibrosis based on a study of the International Working Group for Myelofibrosis Research and Treatment. Blood 2008, I I3:2895901.

16. Arora B, Sirhan S, Hoyer JD, Mesa RA, Tefferi A: Peripheral blood CD34 count in myelofibrosis with myeloid metaplasia: a prospective evaluation of prognostic value in 94 patients. $\mathrm{Br} \mathrm{J}$ Haematol 2005, I 28:42-8.

17. Reilly JT, Snowden JA, Spearing RL, Fitzgerald PM, Jones N, Watmore A, Potter A: Cytogenetic abnormalities and their prognostic significance in idiopathic myelofibrosis: A study of 106 cases. Br J Haematol 1997, 98:96-102.

18. Miller JB, Testa JR, Lindgren V, Rowley JD: The pattern and clinical significance of karyotypic abnormalities in patients with idiopathic and postpolycythemic myelofibrosis. Cancer 1985, 55:582-91.

19. Demory JL, Dupriez B, Fenaux P, Laï JL, Beuscart R, Jouet JP, Deminatti $M$, Bauters F: Cytogenetic studies and their prognostic significance in agnogenic myeloid metaplasia: a report on 47 cases. Blood 1988, 72:855-9.
20. Tefferi A, Mesa RA, Schroeder G, Hanson CA, Li Ch-Y, Dewald GW: Cytogenetic findings and their clinical relevance in myelofibrosis with myeloid metaplasia. Br J Haematol 200 I, I I3:763-7 I.

21. Thiele J, Kvasnicka HM, Facchetti F, Franco V, van der Walt J, Orazi A: European consensus on grading bone marrow fibrosis and assessment of cellularity. Haematologica 2005, 90: I I 28-32.

22. Thiele J, Vardiman JW, Pierre R, Brunning RD, Imbert M, Flandrin G: Chronic idiopathic myelofibrosis. In World Health Organization Classification of Tumours. Pathology and Genetics. Tumours of Haematopoietic and Lymphoid Tissues. Edited by Jaffe ES, Harris NL, Stein H, Vardiman JW. Lyon France: IARC Press; 200I:35-38.

23. Vener C, Fracchiolla NS, Gianelli U, Calori R, Radaelli F, lurlo A, Caberlon S, Gerli G, Boiocchi L, Deliliers GL: Prognostic implications of the European consensus for grading of bone marrow fibrosis in chronic idiopathic myelofibrosis. Blood 2008, I II:I862-5.

24. Campbell PJ, Griesshammer M, Döhner K, Döhner H, Kusec R, Hasselbalch HC, Larsen TS, Pallisgaard N, Giraudier S, Le BousseKerdilès MC, Desterke C, Guerton B, Dupriez B, Bordessoule D, Fenaux P, Kiladjian JJ, Viallard JF, Brière J, Harrison CN, Green AR, Reilly JT: V6I7F mutation in JAK2 is associated with poorer survival in idiopathic myelofibrosis. Blood 2006, 107:2098-100.

25. Barosi G, Bergamaschi G, Marchetti M, Vannucchi AM, Guglielmelli $P$, Antonioli E, Massa M, Rosti V, Campanelli R, Villani L, Viarengo G, Gattoni E, Gerli G, Specchia G, Tinelli C, Rambaldi A, Barbui T; Gruppo Italiano Malattie Ematologiche Maligne dell'Adulto (GIMEMA) Italian Registry of Myelofibrosis: JAK2 V6I7F mutational status predicts progression to large splenomegaly and leukemic transformation in primary myelofibrosis. Blood 2007, I I 0:4030-6.

26. Tefferi A, Lasho TL, Schwager SM, Steensma DP, Mesa RA, Li CY, Wadleigh M, Gary Gilliland D: The JAK2 V6I7F tyrosine kinase mutation in myelofibrosis with myeloid metaplasia: lineage specificity and clinical correlates. Br J Haematol 2005, I 3 I:320-8.

27. Huang J, Li CY, Mesa RA, Wu W, Hanson CA, Pardanani A, Tefferi A: Risk factors for leukemic transformation in patients with primary myelofibrosis. Cancer 2008, I I 2:2726-32.

28. Sorror M: Impacts of pretransplant comorbidities on allogeneic hematopoietic cell transplantation (HCT) outcomes. Biol Blood Marrow Transplant 2008, I 5(Suppl I): |49-53. 